\title{
GSM based Needleless Blood Glucose Monitoring System
}

\section{Mohi-ud-din Q}

Department of Bio-Medical Engineering, Bharath University, Chennai, Tamil Nadu, India

*Corresponding author: Mohi-ud-din Q, Department of Bio-Medical Engineering, Bharath University, Chennai-73, Tamil Nadu, India, Tel: 8803056860; E-mail: qaysar007@yahoo.in

Received date: May 22, 2017; Accepted date: June 25, 2017; Published date: July 5, 2017

Copyright: (C) 2017 Mohi-ud-din Q. This is an open-access article distributed under the terms of the Creative Commons Attribution License, which permits unrestricted use, distribution and reproduction in any medium, provided the original author and source are credited.

\begin{abstract}
Diabetes is one of the leading non communicable diseases affecting public health. Though it is termed as a deficiency rather than a disease, uncontrolled diabetes will lead to complications resulting in renal failure/liver failure/ heart-attack/loss of sight or foot problems leading to amputation if not diagnosed, monitored and treated on time. In order to avoid these complications blood glucose level should be periodically monitored. Conventional methods used for this purpose uses sharp needle which leads to loss of blood and has a risk of infections to the patients. In order to overcome such problems, a non-invasive glucose monitoring system is necessary. In this study, we propose a design, a cost effective and non-invasive glucose monitoring device using near infrared spectroscopy techniques. In addition, GSM module attached to this device will enable wireless data sharing facility. The results can therefore also be transmitted easily to the doctor for examination. The results obtained can also be stored for future records and also to analyse variations in blood glucose level and adjustment of dosage of medicine. The current study shows that our device has accuracy level equivalent to that of conventionally available devices and also provides convenient, hassle free usage to the patients.
\end{abstract}

Keywords: Diabetes; Blood glucose; GSM module; Non-invasive method

\section{Introduction}

Diabetes is one of the biggest challenges faced by the people in the 21 st century which has affected millions of people worldwide [1]. It is responsible for the cause of blindness, heart disease, stroke, obesity and renal failures [2]. Blood glucose is the main source of energy in our body. Glucose is produced from the food we eat. Diabetes affects body's ability to produce insulin, which is a hormone that is needed to process blood glucose in our body [3]. Diabetes is caused when our body's sugar level or glucose level is high. Insulin is a hormone produced by pancreas which helps the blood to carry glucose to all cells in our body. Sometimes our body doesn't produce enough insulin causing glucose to stay in our blood without reaching the body's cells. Thus blood glucose levels in our body gets too high causing diabetes $[4,5]$. As a result, blood sugar level should be kept under control by following strict diet and insulin injections [3]. Periodic and selfmonitoring of blood glucose level is necessary for the patients suffering from diabetes [6]. There are mainly three types of diabetes namely, type1, type 2 and gestational diabetes [7,8]. In type 1 diabetes, pancreas cannot produce enough insulin as the $\beta$ cells in pancreas are destroyed, so the pancreas cannot produce sufficient insulin needed by the body, It is also known as insulin dependent diabetes or Juvenile diabetes [9]. In type 2 diabetes, the body is unable to use the secreted insulin since the cells cannot absorb glucose because of the problems with receptors [10]. It is also known as non-insulin dependent or adult onset diabetes [11]. Gestational diabetes occurs during pregnancy, which leads to type 2 diabetes after delivery [12]. Gestational diabetes occurs during pregnancy as a result of hormonal changes in the pregnant mother, it develops during the middle stage of pregnancy [13].

\section{Methods of monitoring blood glucose}

Blood glucose monitoring is very important to keep glucose level under check, but diabetes cannot be cured. Blood glucose monitoring methods can be classified into two methods; they are invasive glucose monitoring method and non-invasive glucose monitoring method [14].

Invasive glucose monitoring method is the most common method used for monitoring blood glucose level. It involves pricking of hands or fingers to monitor glucose level. The blood from the patient is taken and given to disposable test-strip, which calculates the blood glucose concentration [15].

Non-invasive glucose monitoring method is the most recently advanced method for glucose monitoring which is being studied and further researches are carried out. Polarimetry, Raman spectroscopy, photo acoustic spectroscopy, Mid-infrared spectroscopy and Nearinfrared spectroscopy, Fluid extraction from skin Optical rotation of polarized light are some common methods used for non-invasive blood glucose monitoring [16].

\section{Glucose measurement by near-infrared spectroscopy}

Non-invasive Near-Infrared Spectroscopy (NIR) has been applied for monitoring blood glucose level. NIR has been applied in medical field for glucose monitoring. It uses light within the range of 750-2500 $\mathrm{nm}$. NIR radiation at $1500 \mathrm{~nm}$ was used because of the minimum attenuation of optical signal by constituents like water etc. at this wavelength range and desired depth of penetration can be obtained. LED sensor is used instead of laser as it overcomes all limitations by laser. The Near-infrared radiations have been applied to measure glucose concentrations of blood of the patients [17].

Near Infrared transmittance spectroscopy is used across ear lobe or finger to measure glucose level. Transmittance spectroscopy consists 
of a light source and light detector placed on either sides of ear lobe or finger. The ear lobe was chosen because of its small thickness and also because of the absence of bony tissues [18]. Near infrared light (NIR) was passed on one side of ear lobe or finger while on the other end receiver receives the attenuated light. The attenuated signal is processed and sampled. RC low pass filter connected to photodiode's output reduces high frequency noise [19]. The variations of glucose concentrations in blood, affects the scattering of light. Light is scattered due to the difference in refractive index of blood cells $(1.350-1.360)$ and refractive index of extracellular fluids (1.348-1.352). When concentration of glucose in blood increases, the refractive index of extracellular fluids increases and hence results in decreased light scattering. The scattering coefficient decreases resulting in shorter optical path.

\section{Methodology}

This design uses near infra-red spectroscopic technique to detect the amount of glucose in blood. A sensor giving infra-red radiation of $1550 \mathrm{~nm}$ wavelength, which penetrate through the tissue and the attenuated signal get detected by the photo-detector. The digital sensor with inbuilt Analog to Digital converter has an Infra-red transmitter and Infra-red receiver. The sensor is used on finger-tip or ear lobe to measure glucose concentration of blood. The attenuated signal which the sensor detects is passed through RC filter to remove the noise. The signal is then amplified, and processed by AT89s52 microprocessor and the output is shown on LCD. In addition of displaying glucose levels, the data can be shared by a GSM module and can be sent to the doctor for patient investigations. The GSM module connected with the microprocessor tracks the location of the patients and when the blood glucose levels of patients are above the normal values or below the normal values, it sends the blood glucose level of patient with the doctor and family members.

When the glucose sensor begins to operate, the 230v AC voltage is converted into $12 \mathrm{v}$ by step down transformer and is converted into $12 \mathrm{v}$ DC voltage by bridge amplifier and voltage regulator. The glucose concentration is detected by the amount of light attenuation after interacting with the tissue. The detected voltage signal is amplified and passed into microprocessor. Glucose absorption coefficients and scattering coefficients are calculated. The programs in AT89s52 microprocessor are executed in Embeded c. The programs are executed continuously and the resultant glucose level is displayed on a display device (Figures 1 and 2).

\section{Work flow of non-invasive blood glucose monitor}

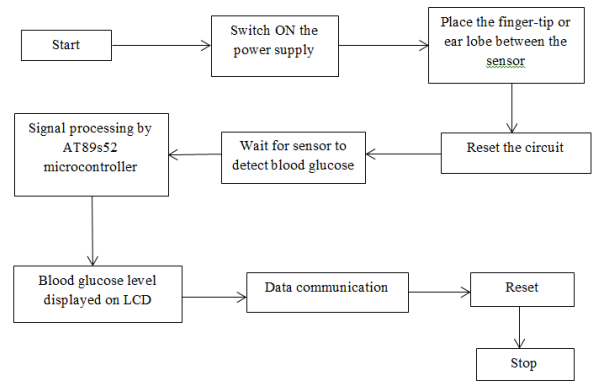

Figure 1: Work flow of non-invasive glucose monitoring system.

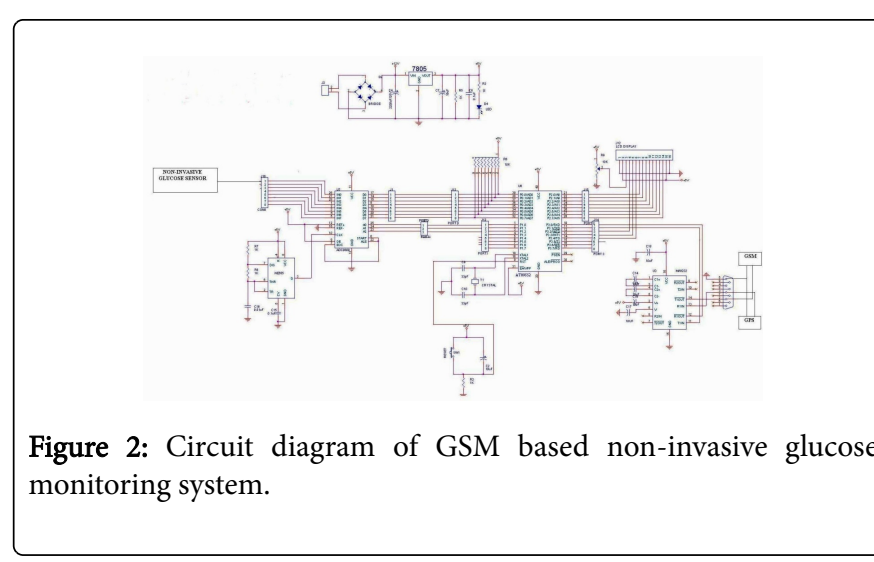

\section{Results and Discussion}

The non-invasive blood glucose monitor designed contains a sensor unit, processing unit and display unit. The sensor unit also acts as a transducer which detects the signal from the patients and converts it to the electrical form and transmit it to the processing stage. The processing stage sends the processed data to the output unit to display the results. The sensor used here is an optical IR digital sensor which is clipped with finger of the patients. The sensor contains transmitter and receiver on both the ends respectively. The below given Figure 3 shows the hardware model of GSM based non-invasive blood glucose monitoring system.

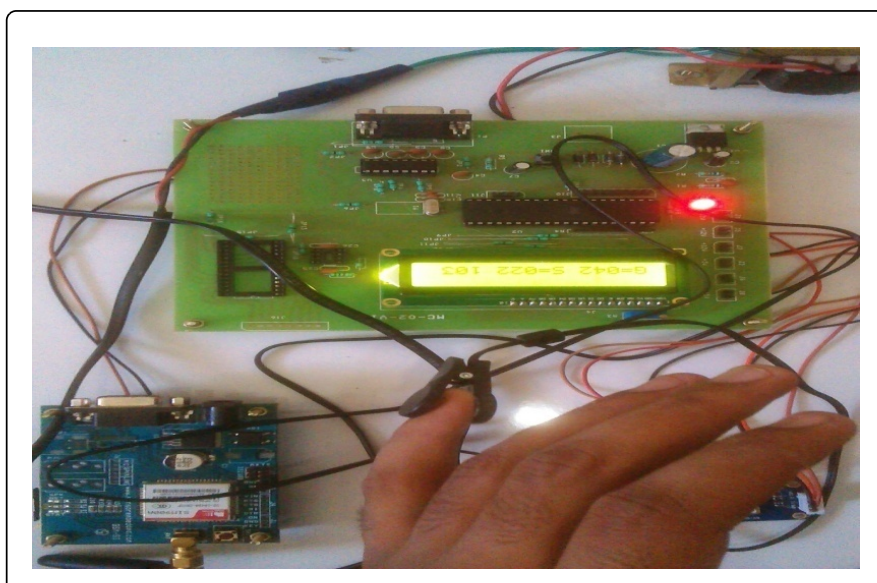

Figure 3: Hardware model of GSM based non-invasive glucose monitoring system.

The glucose levels of patients are displayed on LCD. After the results are processed, they are displayed. A processing time of about 60 seconds is required for the LCD to display the results. The obtained results shown on LCD after 60 s can be stored and are transmitted and received using the GSM module.

After the design, we have to check its accuracy. For its accuracy, we measured the glucose level of the patients both invasively and noninvasively. Around 15 patients were checked for their glucose levels before meals (both invasive and non-invasive) followed by 90 minutes after meals (both invasive and non-invasive). Below Figure 4 shows graphical representation of both invasive and non-invasive glucose level results of patients before meal. Invasive and non-invasive results of patients after meal are given in Figure 5. Both invasive and non- 
Page 3 of 4

invasive random results are compared in Figure 6 which are given below.

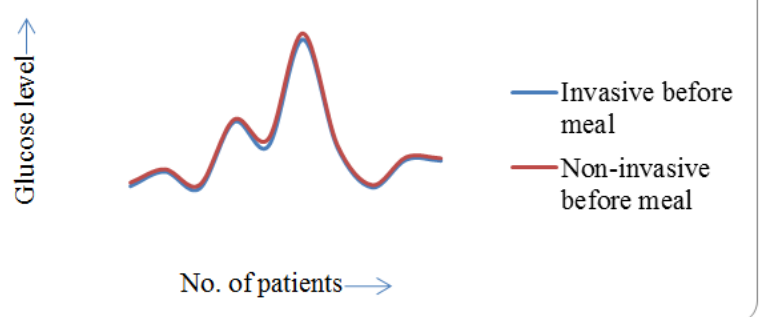

Figure 4: Graph showing invasive and non-invasive results of patients before meal.

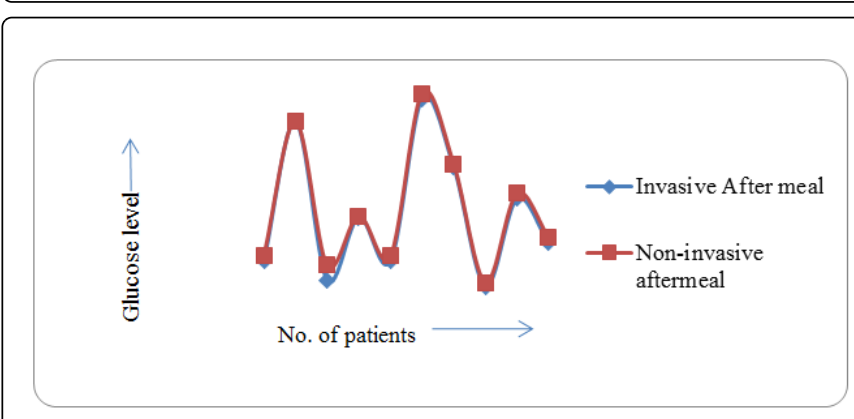

Figure 5: Graph showing invasive and non-invasive results after meal.

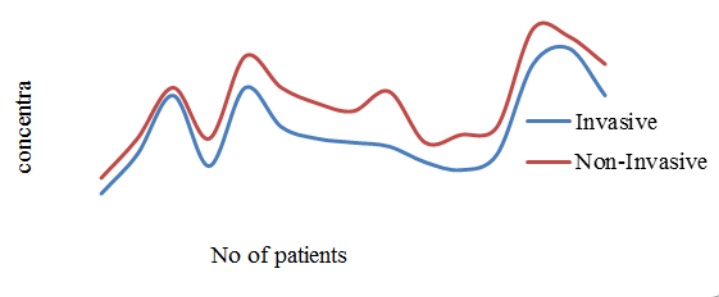

Figure 6: Graph showing comparison of invasive and non-invasive random results.

The concentration of glucose increases in the blood after having food because when we intake carbohydrate rich food, our body breaks down the sugar they contain into glucose. Our body can't absorb much sugar without breaking them down first. Simple sugars breaks down quickly which can be absorbed rapidly in our bloodstream thus raising our blood sugar.

The results obtained from these two methods were compared and we observed that the non-invasive system designed by us was found more than $99.5 \%$ accurate as compared to the invasive system.

\section{Conclusion}

This technique eliminates the risk of spreading infections by finger pricking and is more comfortable and low cost than invasive technique. It provides an easy way of measuring blood glucose levels of the diabetic patients at home and even without the need of a specialist to monitor blood glucose level. Current invasive methods cause lots of pain and cannot be used for continuous blood glucose monitoring. Continuous blood glucose monitoring is possible without even finger pricking easily by just placing the sensor on the finger-tip.

Our design provides the data sharing facility to transmit the patient glucose level and location to the doctor for patient investigations. The accuracy of the design is similar to that of the currently available invasive methods.

\section{Future Scope}

With the addition of battery this design can monitor blood glucose levels while travelling or when the external current is not available. Further the processing time needed by LCD which is 60 seconds in our design can be further decreased by caliberation. It can be also provided with a dark box to place the sensor to prevent external light from passing through it as sensor contains a photo-detector, which detects IR light emitted by photo-emitter passing through the blood which can get attenuated by external light. A tight band can be worn over the hands to prevent them from shaking inorder to prevent disturbances in blood flow and hence more accurate results can be obtained.

\section{References}

1. Wild S, Rogli G, Green A, Sicree R, King H (2004) Global Prevalence Of Diabetes: Estimates for the year 2000 and projections for 2030. Diabetes Care 27: 53-100.

2. Nathan DM, Genuth S, Lachin J, Cleary P, Crofford O, et al. (1993) The effect of intensive treatment of diabetes on the development and progression of long-term complications in insulin-dependent diabetes mellitus. N Engl J Med 77: 977-986.

3. Kitabchi AE, Umpierrez GE, Fisher JN, Mary BM, Eugene BJ, et al. (2001) Management of hyperglycaemic crises in patients with diabetes. Diabetes Care 24: 131-153.

4. Coster S, Gulliford MC, Seed PT, Powrie JK, Swaminathan R (2000) Monitoring blood glucose control in diabetes mellitus: A systemic review. Health Technoloy Assesment 4: 12-30.

5. White NH (2000) Diabetic ketoacidosis in children. Endocrinol Metab Clin North Am 29: 657-682.

6. Wolfsdorf J, Glaser N, Sperling MA (2006) Diabetic ketoacidosis in infants, children, and adolescents: A consensus statement from the American Diabetes Association. Diabetes Care 29: 1150-2259.

7. Skyler JS, Ricordi C (2011) Attempts to prevent or cure type 1 diabetes in man. Diabetes Research institute university of Miami 60: 1-8.

8. Kai W, Eisenbarth GS (2005) Type 1 diabetes. Nature 32: 16-30.

9. Young L, Wang May Y, Xiu Q, Charron MJ, Unger RH (2010) Glucagon receptor knockout prevents Insulin deficient type-1 diabetes in mice. Diabetes 60: 391-397.

10. de Boer IH, Sun W, Cleary PA, Lachin JM, Molitch ME, et al. (2011) Intensive diabetes therapy and glomerular filtration rate in type 1 diabetes. N Engl J Med 365: 2366-2376.

11. Jacobson AM, Musen G, Ryan CM, Silvers N, Barbara W, et al. (2007) Long-term effect of diabetes and its treatment on cognitive function. $\mathrm{N}$ Engl J Med 356: 52-1842.

12. Miles JM, Gerich JE (1983) 3 Glucose and ketone body kinetics in diabetic ketoacidosis. Clin Endocrinol Metab12: 303-319 
Citation: Mohi-ud-din Q (2017) GSM based Needleless Blood Glucose Monitoring System. J Bioengineer \& Biomedical Sci 7: 231. doi: $10.4172 / 2155-9538.1000231$

Page 4 of 4

13. Burge MR, Hardy KJ, Schade DS (1993) Short term fasting is a mechanism for the development of euglycemic ketoacidosis during periods of insulin deficiency. J Clin Endocrinol Metab 76: 1192-1198.

14. Nir T, Melton DA, Dor Y (2007) Recovery from diabetes in Mice by $\beta$ Cell Regeneration. J Clinical Investigation 32: 2553-2561.

15. Schranz DB, Lernmark A (1998) Immunology in diabetes. Department of Medicine, University Of Washington.

16. Boomer Rolf (2013) Treating type 1 diabetes with stem cells. Neuroscience ageing and Stem Cell Research Center 46: 57-73.

17. Giovannucci E, Harlan DM, Archer MC, Richard MB, Susan MG, et al. (2010) Diabetes and cancer: A consensus report. CA Cancer J Clin 60: 207-221.
18. Holman RR, Thorne KI, Farmer AJ, Davies MJ, Joanne FK, et al. (2007) Addition of biphasic, prandial or basal insulin to oral therapy in type 2 diabetes. NEngl J Med 357: 1716-1730.

19. Lee AJ, Hiscock RJ, Wein P, Walker SP, Permezel M (2007) Gestational diabetes mellitus: Clinical predictors and long-term risk of developing type 2 diabetes: A retrospective cohort study using survival analysis. Diabetes Care 30: 83-878. 